\title{
Using "Sustainable Development" Computer Program to Determine the Environmental Safety of the Regions
}

\author{
I.O. Soloshych ${ }^{1 *}$, S.I. Pochtovyuk ${ }^{1}$ \\ ${ }^{1}$ Kremenchuk Mykhailo Ostohradskyi National University \\ *Corresponding author E-mail: soloishych@gmail.com
}

\begin{abstract}
The article is devoted to the problem of determining the environmental safety of the country or its regions. It has been shown that existing software provides for automatic identification of only individual indicators or constituents of environmental safety. To eliminate these shortcomings, a methodology for assessing the environmental safety of the country or its regions has been substantiated and a model for building "Sustainable Development" software program has been developed. The paper gives the examples of the application of the developed "Sustainable Development" software program, which uses a system of basic indicators, combined in homogeneous groups economic, social, and environmental. The use of the software for any country in the world is substantiated, provided that the relevant empirical data are entered in order to develop the strategic purposes of the development of the regions and the entire country.
\end{abstract}

Keywords: "Sustainable Development" software application; environmental safety of the country or its regions; social, environmental and economic condition.

\section{Introduction}

The subject of scientific research of the last decade has been increasingly aimed at finding optimal conditions for the interaction of economic complex and socio-environmental and environmental systems.

The process of the environmental deterioration negatively affects the health and quality of life of people and poses threats to national security in the social, economic and environmental aspects.

Therefore, in today's world space, the issue of international environmental security, which is characterized by a new dimension in the context of a strategy for the implementation of sustainable development of society, becomes particularly challenging and urgent.

The concept of sustainable development of the country or its regions allows to ensure stable and balanced development of economic, environmental and social sectors of life, which are united into a holistic system of principles of economic efficiency, environmental safety and social protection.

The condition of urban ecosystems is changing rapidly. In this regard, it is necessary not only to carry out comprehensive studies of contamination of components of the environment, but also their systematic analysis and forecasting of environmental safety indicators in order to identify strategic goals and develop action plans for their implementation.

Since socio-environmental and economic researches are accompanied by a large amount of diverse information, the development of automated analytical computer systems for the processing of environmental data and integrating environmental safety indexes is vital for the effective control of the socio-environmental and economic status of the territories.

Automated processing of environmental safety of regions should be implemented with the use of modern computer technologies and include:
- systematization of data in a properly organized computer database;

- complex processing of the database and creation of the model of the condition of the territory;

- automated calculation of complex and aggregate indicators summarizing research results;

- visualization of social, environmental and economic data and results of processing the database in the form of diagrams, maps, schemes that best reflect the state of the territory and provide an opportunity to constantly monitor its changes.

\section{Problem Statement}

The analysis of researches [1-8] suggests that at present information provision to the society and governmental institutions of environmental safety does not satisfy the necessary modern requirements, which complicates the process of making managerial decisions.

There is a lack of information retrieval, expert and analytical information-calculation computer systems. Therefore, it is important to develop analytical information systems, their separate components, which will allow assessing the level of environmental safety on a unified methodological basis.

Hence the emergence of the scientific task of creating of a computer program "Sustainable Development" (the Program), which would provide an assessment of sustainable development of the country or its regions to determine their environmental safety. In order to determine the environmental safety of the country or its regions, as a rule, various data processing software is used, such as Statistica, SPSS, BMDP, SPAD, STATGRAPHICS [1, 2].

Their advantages in the calculation of environmental safety are that they have a sufficient amount of statistical functions and means of visual representation of the data in the form of diagrams, graphs, as well as display of research results on geographic maps. 
However, it is often necessary to use several software programs or platforms to calculate and analyze the environmental performance of a country or region:

- table processors can be used for data input and initial processing [2];

- SPSS, Statistica or Vorte are used for the analysis of observational data, depending on the necessary statistical and mathematical functions $[1,2]$;

- AnyLogic, Vensim, Visual Studio environment are used at the final stage - computer simulation of the ESR $[1,3]$.

The analysis of the scientific works makes it possible to state that the calculation and analysis of environmental safety is usually done using software, without taking into account the environmental component.

Based on the research results, software programs "Midas" and "ISDC-Lab" are most commonly used. They provide an opportunity to perform analysis of the sustainable development of the individual systems $[4,5]$.

For example, the MIDAS program [4] carries out calculations of indicators of sustainable development, taking into account data of only social and economic systems.

It has a user-friendly interface, a powerful mathematical instrument that allows one to perform and analyze results, visualize and graphically represent them.

To store data in the process of solving tasks, the database management system WFile is used, which definitely requires additional skills and appropriate qualifications of a specialist-ecologist from the user.

According to the definition of the ES, the "MIDAS" program can be used to model the indicators of economic and social components by the main components method.

In the context of the definition of environmental safety, the computer program "ISDC-Lab" (Laboratory of Index of Sustainable Development of Company) [5], built on the platform of the program $1 \mathrm{C}$ version 8.2 , provides an opportunity to calculate all indicators of the socio-environmental and economic system (SEES), the creation of the necessary journals, the receipt of results in the form of a graphic image "Quadrilateral Sustainable Development". But its disadvantage is that it defines only the sustainable development index of an enterprise, not the country.

Based on the results of the research $[6,7,8]$ it is determined that for the calculation of the environmental component of the SEES there are the following software tools:

- ECOPHONE - for calculations of the regional environmentalgeochemical background, anomalies and isoconcentrates [6];

- ECOSAFATYGEOSYSTEMS - for calculating pollutant concentration intervals for environmentally safe existence of geosystems [6];

- Program complex "ERA" - for solving problems in the field of air, water, waste management, etc. [Programs for ecology and nature protection. Official site https://lpp.ru];

- AERMOD - for modeling the spread of pollutants from various sources of emissions [7];

- Automated systems for calculating atmospheric pollution "EOL", "Garant-1" and others - to assess the impact of harmful emissions of enterprises [8].

An analysis of sources [1-4, 7-8] suggests that most of them provide an opportunity to automatically identify only individual indicators or constituents of the environmental safety of regions.

Consequently, the task of creating a program that takes into account all the components of the environmental safety of the development of countries or its region remains unresolved.

\section{The Purpose and Tasks of the Study}

The purpose of the paper is to build a program that provides an assessment of the environmental safety of the country as a whole and its individual regions.

To achieve this goal, the following tasks were solved:
- substantiation of the problem of assessing the country's environmental safety by means of a computer program;

- construction of the model of the Program;

- development of the Program (database, computational algorithms and their program realization).

\section{Results of Research}

Solving the task of determining the object of the study was conducted by summarizing information on existing methods and software tools for assessing the environmental safety of the country as a whole and its individual regions on the basis of its sustainable development.

In accordance with the methodology of integrated environmental safety assessment, the algorithm of calculation involves four levels of assessment and aggregation of indicators [9]:

- assessment of statistical informative baseline indicators (BI) that characterize the socio-environmental and economic state of the subsystem of the environment:

- estimation of aggregate indicators (AI), which characterize the condition of related group (macroindicators) studied subsystems;

- evaluation of integrated indicators (II) that characterize the socio-environmental and economic state of the subsystem;

- Integral index of socio-environmental and economic development of territories (ISEEDT).

Based on the definition of the "modelling" concept by the scientists [9] for constructing the Program, the model has been developed, that is: a set of views, positions and decisions necessary for purposeful and optimal solution of tasks of theoretical research and their practical implementation, containing the purpose, conceptual apparatus, methodological basis, principles and results in Figure 1

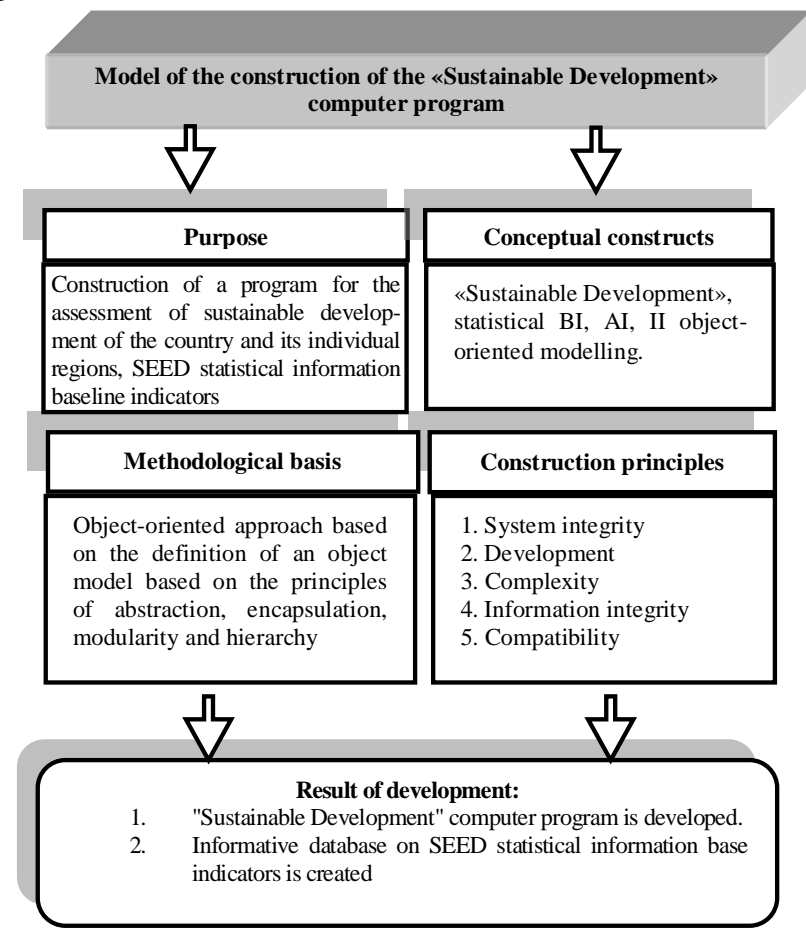

Fig. 1: Model of the construction of «Sustainable Development» software The main purpose of the model was to develop a Program for assessing the environmental safety of the country as a whole and its individual regions, socio-environmental and economic statistical information base indicators that characterize the socioenvironmental and economic state of the subsystems of the environment.

The methodological basis of the model is the object-oriented approach in programming, which views the program as a set of in- 
teracting objects, each of which represents a particular class, and classes are members of a certain imitation hierarchy [10].

One of the cornerstones of the program's construction is the definition of a research methodology, which is a theoretical basis.

An analysis of literary sources [10, 11, 12, 13, 14] allowed us to conclude that the most successful and comprehensive method is a comprehensive assessment of environmental safety, proposed by L. V. Klymenko [14], which is the basis of our study.

A large amount of data is usually used when calculating the environmental safety of the socio-environmental and economic status, which results in significant quantitative calculations that are optimized when using the Program.

Sustainable Development [15] can be used both by specialists in defining environmental safety, modeling the sustainable development strategy of the country, and by students of the environmental field during their implementation of the scientific research.

Software implementation is described in paper [15]. Programs can have both Ukrainian and English interfaces depending on the user's choice of the corresponding parameter.

The Program was designed in such a way that minimum system and technical requirements were required for its proper operation and operation, namely: operating system: Windows XP / Vista / 7/8/10; processor: Pentium $3800 \mathrm{MHz}$ (similar or later model); RAM: $512 \mathrm{MB}$ or more); video memory: $32 \mathrm{MB}$; free hard disk space: $1 \mathrm{~GB}$; monitor with a $1366 \times 768$ resolution. In addition, general-purpose application software MS Office is required to work with the Program.

When developing the Program taking into account methodological developments suggested by A. Shapara, the following indicators are used to characterize the environmental development of the region when calculating environmental safety [16]:

- the indicator of the state of the air (total emissions, pollutant emissions from stationary sources, emissions of pollutants from mobile sources, emission density, emissions per person);

- indicator of water resources use (use of fresh water, volume of reversible and consecutive (re)used water, dumping of insufficiently treated back water into natural water surface objects);

- the indicator of waste management (the presence of waste, the generation of waste I-IV classes of danger).

Economic development of the region is calculated on the basis of: - gross domestic product per capita;

- index of industrial production;

- the index of internal aggregate real demand;

- the index of gross consumption, the share of the extractive industry in the volume of industrial production;

- shares of the manufacturing industry in the volume of industrial production;

- volume of aggregate investment in fixed assets;

- coefficient of intensity of renewal of fixed assets;

- volume of scientific research, scientific and technical works;

- import and export of goods and services;

- volume of foreign investments.

The main indicators of social development of the regions are:

- protection of living standards (number of invalids, number of registered crimes);

- demographic indicators (number of births, number of deceased persons, natural reduction);

- housing maintenance of the population (population provision with housing (on average per person, $\mathrm{m}^{2}$ of the total area)).

Assessment of environmental safety of socio-environmental and economic status is carried out using a system of basic indicators, combined in a homogeneous group (economic, social, environmental).

According to the influence on the socio-environmental and economic status, two types of indicators are distinguished: positive (X) and negative (X1), which determine the quantitative values of growth and decrease of the integral assessment of the lower level blocks.
For positive indicators, the increase of their quantitative values determines the growth of the integral assessment of lower-level blocks:

$$
X=\frac{N_{i}-N_{i}(\min )}{N_{i}(\max )-N_{i}(\min )}
$$

For a negative indicator of decreasing their quantitative values, it causes improvement of the state of lower level blocks:

$$
X 1=\frac{N_{i}(\max )-N_{i}}{N_{i}(\max )-N_{i}(\min )} \cdot
$$

On the basis of the proposed hierarchical structure, we choose the algorithmic scheme for calculating the integral level of socioenvironmental and economic development of the territory. At the heart of the calculation is the gradual "curtailment" of the values of the indicators for the lower and intermediate levels.

At the same time, the "curtailment" of the basic into aggregated, aggregated into integrated and integrated into integral indicators was carried out using the formula of the average geometric:

$x=\sqrt[n]{\prod_{i=1}^{n} \cdot x}$

It should be noted that each of the basic indicators has its own nature and, above all, the maximum and minimum limits of fluctuations: $\mathrm{Ni}(\max )$ and $\mathrm{Ni}(\min )$.

Quantitative values of indicators were taken for the maximum positive and minimum negative that corresponded to the best values of typical administrative units in the region.

Taking into account the presence of positive and negative types of indicators, the basic indicators are given to the normalized form and the aggregate indicators are defined as the geometric mean of the basic indicators [9].

The algorithm for calculating the indices of the socioenvironmental and economic condition of the region includes four main levels of assessment and aggregation of indicators:

- the first one - provides an estimation of statistical informative basic indicators that characterize the state of the socioenvironmental-economic subsystem;

- the second - aggregate indicators, which are calculated from several basic and characterize the state of related group (macroindicators) socio-environmental and economic subsystem:

$$
A \Pi=\sqrt[n]{5 \Pi_{1} * 5 \Pi_{2} * \ldots * 5 \Pi_{n}}
$$

- the third - the assessment of integrated indicators, which are calculated on the basis of a number of aggregate indicators and characterize the state of the socio-environmental and economic subsystem:

$$
I=\sqrt[n]{A \Pi_{1} * A \Pi_{2} * \ldots * A \Pi_{n}}
$$

- the fourth - the index of socio-environmental and economic development of the region:

$I C E E P T=\sqrt[3]{I_{1} \cdot I_{2} \cdot I_{3}}$,

where: $I_{1}$ - integrated indicator of social development of the populated area; $\mathrm{I}_{2}$ - integrated indicator of economic development of the populated area; $\mathrm{I} 3$ - integrated indicator of environmental development of the populated area.

The Sustainable Development computer program is designed in such a way that the main window, which contains the main menu 
and tabs of all three components ("Social component", "Environmental component", "Economic component") and "Result" is opened immediately after its launch.

The first three tabs serve to calculate the index of the status of a component in a particular area.

To calculate the indicators by their own data, they are entered into the corresponding fields. In addition, the user can insert data into an Excel file and they will also be downloaded into the program (Figure 2).

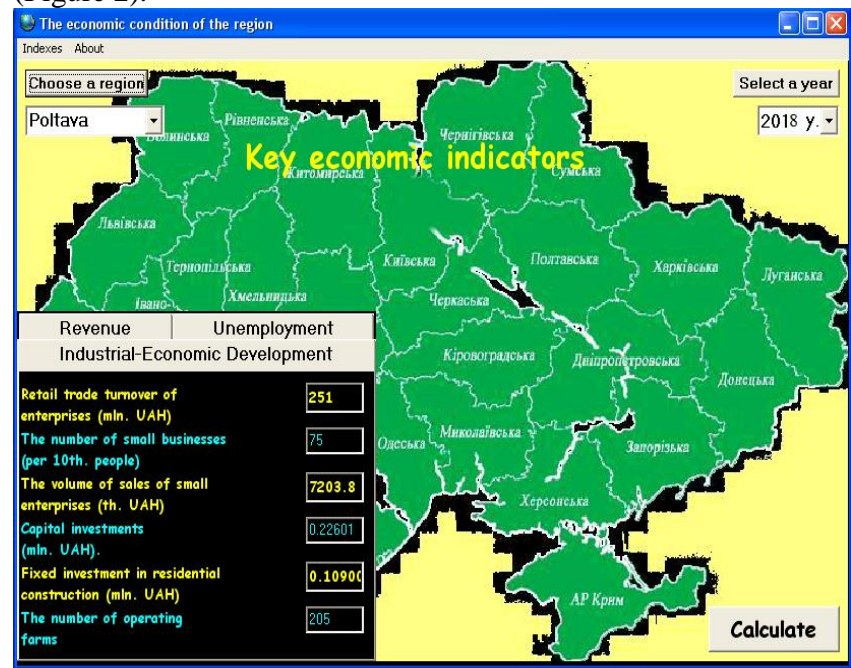

Fig. 2: An example of entering data into a computer program "Sustainable Development"

When entering basic data, that is also stored in *.xls files, it is automatically saved.

The "Result" tab is used to obtain an integrated socioenvironmental and economic status of a particular region, provided that three components are calculated.

After selecting the necessary component of the Program, the following information is selected: year, region, and area of study (the relevant data is downloaded into the program).

The result of computing the index of the selected component is available in numeric, text and graphic formats.

To work correctly with Excel files, the program has its own templates for creating new files.

This program implements filters that control the type and dimension of the information entered. If an incorrect entry is made by the user, an appropriate information message or error message is displayed.

Therefore, for the calculation of the country's or its individual regions' environmental safety using the Program, the following steps are taken:

- calculation of basic, aggregated, integrated indicators and index of socio-environmental and economic development of the rayon, region;

- the output of the index of the socio-environmental and economic development of the rayon on the map, accompanied by the definition of the state according to the scale (critical, threatening, satisfactory, favourable), their respective colour and text inscription;

- calculation of the index of socio-environmental and economic development of the country, using the index of each region.

In Figures 3 and 4, examples of the definition of aggregate and integrated indicators of the economic development of the region with the use of "Sustainable Development" computer program are given respectively.

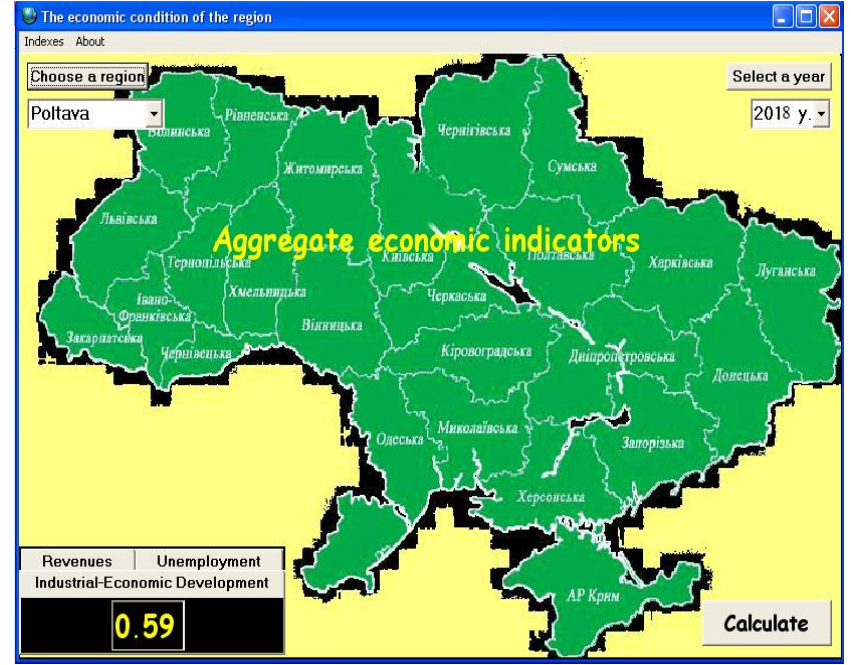

Fig. 3: An example of determining the aggregate indicator of the economic development of the region

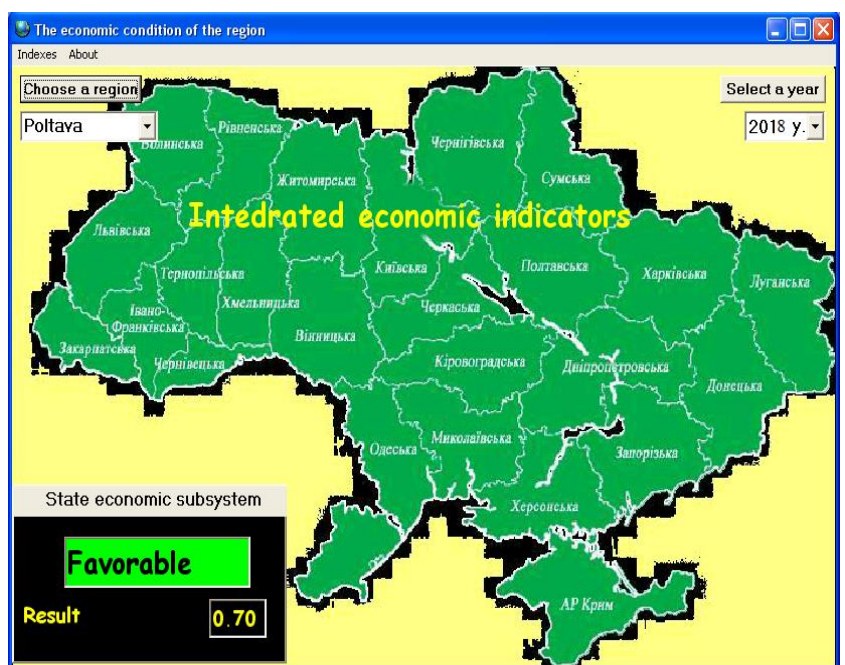

Fig. 4: An example of the definition of an integrated indicator of the economic development of the region

To calculate the socio-environmental and economic development index for the country as a whole, there is a tab "Calculation for the country", turning to which program will gradually begin to calculate and display the results of the index of socio-environmental and economic development of each region.

At the end of all calculations, the index of socio-environmental and economic development of the country is determined, with the output of its numerical indicator by regions and painted in the corresponding colour (Figure 5, the example of Ukraine).

On the basis of the data obtained using the SWOT analysis, in order to develop strategic and operational goals (priorities) of socio-environmental and economic development of regions and the country as a whole [17] the following are determined:

- strong (strengths) internal sides, competitive advantages of the existing features of the region that underlie its development;

- weaknesses of the existing features of the region or country that complicate the conditions for their development;

- opportunities, existing features, conditions favourable to the development of the region or countries that are or may arise in the future;

- threats of existing features, conditions unfavourable to the development of the region, or countries that are or may arise in the future. 


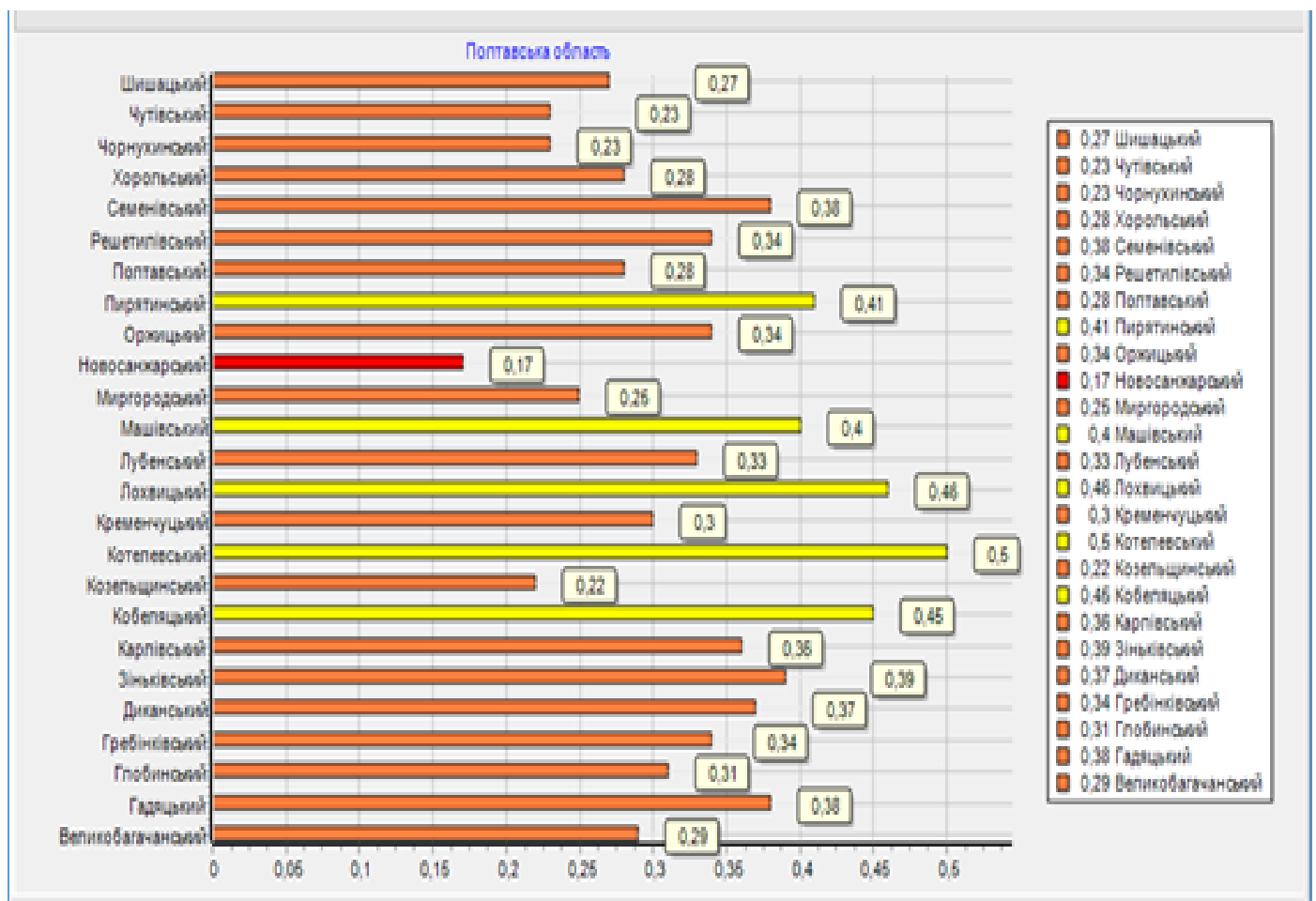

Fig. 5: An example of obtaining the result of calculating the index of socio-environmental and economic development of the country systems and safety of life in the area of influence of oil and gas fields, Environmental safety and balanced use of resource 2(6), (2012), pp:32-53.

\section{Conclusion}

As a result of the research:

1. The methodology for assessing the environmental safety of a country or its regions is substantiated.

Its basis was the assessment of environmental safety, which involves the use of a system of basic indicators, combined in a homogeneous group (economic, social, and environmental).

2. The model of the Program construction, which is a set of views, provisions and decisions necessary for purposeful and optimal solution of the tasks of theoretical research and their practical realization, contains the purpose, conceptual apparatus, methodological basis, principles and results.

3. The application of "Sustainable Development" computer program for assessing the environmental safety of the country or its individual regions is considered, and examples of the country or its regions are given.

4. The presented Program can be used for any country in the world, provided that relevant empirical evidence is provided for the development of strategic goals for the development of regions and the country as a whole.

\section{References}

[1] Romashko SM, Savras IZ, Selivestov RG, Yurinets RV, Simulation of socio-economic development of territories, Kyiv: National Academy of Public Administration, (2013).

[2] Gorbachev AP, Salnikov SA, Analysis of sociological research with SPSS, Lutsk: «Vezha» Volyn National University, (2008), pp. 96-104.

[3] Rumyantsev MI, Comparative analysis of modern methods of simulation modeling, Socio-economic problems of regional development, (2006), pp:118-125.

[4] Midas. Multifactor intelligent dynamic analysis of systems, available online: https://ainst.pro/product-midas.html, last visit 28.01.2018.

[5] Teleshevskaya SM, (2016), Assessment of the factors of sustainable development of enterprises in the bakery industry (Doctoral dissertation), Odesa National University of Economics, Odesa.

[6] Adamenko OM, Mishchenko LV, Zorin DO, Krykhivsky MV, Computer programs for assessing the environmental status of eco-
[7] Programs for ecology and nature protection, available online: https://lpp.ru, last visit: 08.02.2018.

[8] Malko GO, Analysis of software for calculating the impact of transport on the environment, East European Journal of Advanced Technology: integrated strategic management, project and development management of enterprises and territories 1/11 (55), (2012), pp:58-60.

[9] Nekos AN, Soloshich IO, Comprehensive evaluation of regional development as a component of the green economy implementation, Actual problems of the economy 5, (2012), pp:99-112.

[10] Buch G, Maximchuk RA, Engle MW, Young BJ, Coonlane J, Houston KA. Object-oriented analysis and design with examples of applications, Moscow: Williams, (2008).

[11] A new global partnership: eradicate poverty and transform economies through sustainable development. UN Report, 2013, 68pages. available online: http://www.post2015hlp.org/wpcontent/uploads/2013/05/UN-Report.pdf, last visit: 08.06.2013.

[12] Gerasimchuk ZV, (2001), Environmental and economic foundations for the formation and implementation of a regional sustainable development policy (methodology and methodology questions) (Doctoral dissertation), National Academy of Sciences of Ukraine, Institute of Regional Studies, Kyiv

[13] Kovalska LL, Assessment of the region's competitiveness and mechanisms for its improvement, Lutsk: Lutsk State Technical University, (2007).

[14] Klimenko LV, Justification of indicators that characterize sustainable development, Bulletin of the National University of Water Management and Nature Management, Vol.2, No.1, (2006), pp:3-

[15] Pochtovyuk SI, Soloshich IO, (2017), Software application for automated integrated assessment of sustainable development of the region (Version 1), [Computer software], Ukraine: State Intellectual Property Service of Ukraine.

[16] Shapar AG, Contemporary large-scale environmental problems in the context of sustainable development, Ecology and nature management 12, (2009), pp:6-9.

[17] Pryshchepa AM, Brezhitskaya OA, Klymenko LV Sustainable development and basic principles of its achievement, Bulletin of the National University of Water Management and Nature Management 2 (38), (2007), pp:72-78. 